\title{
Iterative algorithm for a common fixed point of two mono-pseudocontractive mappings in Banach spaces
}

\author{
Naseer Shahzad ${ }^{a, *}$, Habtu Zegeye ${ }^{b}$ \\ ${ }^{a}$ Department of Mathematics, King Abdulaziz University, P. O. B. 80203, Jeddah 21589, Saudi Arabia. \\ ${ }^{b}$ Department of Mathematics, Botswana International University of Science and Technology, Private Mail Bag 16,Palapye, Botswana. \\ Communicated by Y. H. Yao
}

\begin{abstract}
In this paper, we introduce an iterative process which converges strongly to a common fixed point of two mono-pseudocontractive mappings in Banach spaces. Our theorems complement the results that have been proved for the class of pseudocontractive mappings in Banach spaces. (C)2017 All rights reserved.
\end{abstract}

Keywords: Monotone mapping, pseudocontractive mapping, mono-pseudocontractive mapping, strong convergence. 2010 MSC: 47H05, 47J05, 47J25.

\section{Introduction}

Let $\mathrm{H}$ be a real Hilbert space. A mapping $\mathrm{T}: \mathrm{C} \rightarrow \mathrm{E}$ is called Lipschitzian if there exists $\mathrm{L} \geqslant 0$ such that $\|T x-T y\| \leqslant L\|x-y\|$, for all $x, y \in C$. If $L=1$, then $T$ is called nonexpansive and if $L \in[0,1)$, then $T$ is called a contraction. A mapping $\mathrm{T}$ is called pseudocontractive if for each $\mathrm{x}, \mathrm{y} \in \mathrm{C}$, we have

$$
\langle x-y, T x-T y\rangle \leqslant\|x-y\|^{2} .
$$

Let $C$ be a nonempty, closed, and convex subset of a real Banach space $E$ with dual $E^{*}$. One direction of extending definition of pseudocontractive mapping in Hilbert spaces to Banach spaces is the following. A mapping $\mathrm{T}: \mathrm{C} \rightarrow \mathrm{E}$ is called pseudocontractive if there exists $\mathrm{j}(x-y) \in \mathrm{J}(x-y)$ such that

$$
\langle T x-T y, j(x-y)\rangle \leqslant\|x-y\|^{2} \text { for all } x, y \in C,
$$

where $J$ is the normalized duality mapping from $E$ into $2^{E^{*}}$ defined by

$$
\mathrm{Jx}:=\left\{\mathrm{f}^{*} \in \mathrm{E}^{*}:\left\langle x, \mathrm{f}^{*}\right\rangle=\|x\|^{2}=\left\|\mathrm{f}^{*}\right\|^{2}\right\},
$$

where $\langle.,$.$\rangle denotes the generalized duality pairing. The single-valued normalized duality mapping is$ denoted by $j$. It is well-known that if $E$ is smooth, then the duality mapping $J$ is single-valued and if

\footnotetext{
*Corresponding author

Email addresses: nshahzad@kau.edu. sa (Naseer Shahzad), habtuzh@yahoo.com (Habtu Zegeye)
} 
$\mathrm{E}=\mathrm{H}$, a real Hilbert space, then $\mathrm{J}$ is the identity mapping on $\mathrm{H}$ and inequality (1.2) reduces to inequality (1.1).

Apart from being an important generalization of nonexpansive mappings interest in pseudocontractive mappings stems mainly from their firm connection with the important class of nonlinear accretive mappings, where a mapping $A$ with domain $D(A) \subseteq E$ and range $R(A)$ in $E$ is called accretive if there exists $j(x-y) \in J(x-y)$ such that

$$
\langle A x-A y, j(x-y)\rangle \geqslant 0 \text { for all } x, y \in D(A) .
$$

We note that $T$ is pseudocontractive if and only if $A:=I-T$ is accretive and thus a fixed point of $T$, $\mathrm{F}(\mathrm{T}):=\{x \in \mathrm{D}(\mathrm{T}): T x=x\}$ is a zero of $A, N(A):=\{x \in D(A): A x=0\}$. It is now well-known that if $A$ is accretive then the solutions of the equation $A x=0$ correspond to the equilibrium points of some evolution systems [42].

A mapping $A: D(A) \subset E \rightarrow 2^{E^{*}}$ is called monotone if

$$
\langle x-y, A x-A y\rangle \geqslant 0 \text { for all } x, y \in D(A) .
$$

If $E=H$, is a real Hilbert space, then the set of monotone mappings is the same as the set of accretive mappings. Interest in monotone operators stems mainly from their usefulness in many functional equations. Many of them appear also in calculus of variations as subdifferential of convex functions (Pascali and Sburian [22]).

In 1953, the most general iterative scheme for the approximation of fixed points of nonexpansive mapping, which is called Mann algorithm, was introduced (in the light of [19]) as follows:

$$
x_{n+1}=\alpha_{n} x_{n}+\left(1-\alpha_{n}\right) T x_{n}, \quad n \geqslant 0,
$$

where the initial guess element $x_{0} \in C$ is arbitrary and $\left\{\alpha_{n}\right\}$ is a real control sequence in the interval $(0,1)$. Construction of fixed points of nonexpansive mappings via Mann's algorithm [19] has extensively been investigated recently in literature (see, e.g., $[4,6,7,11,12,14,16,20,23,25,30,39])$. If $\mathrm{T}$ is a nonexpansive mapping with a fixed point and if the control sequence $\left\{\alpha_{n}\right\}$ is chosen so that $\sum_{n=0}^{\infty} \alpha_{n}\left(1-\alpha_{n}\right)=\infty$, then the sequence $\left\{x_{n}\right\}$ generated by Mann's algorithm (1.3) converges weakly to a fixed point of T (this is indeed true in a uniformly convex Banach space with a Fréchet differentiable norm [23]). However, this convergence is in general not strong (see the counterexample in [8]; see also [10]).

To obtain strong convergence, many iteration processes are often used to approximate a fixed point of a nonexpansive mapping in Hilbert or Banach spaces (for example, see [9] and [4, 6, 7, 11, 23]). One of them is now known as Halpern's iteration process [11] and is defined as follows: let the sequence $\left\{x_{n}\right\}$ be iteratively defined by $x_{0} \in \mathrm{C}$ and

$$
x_{n+1}:=\alpha_{n+1} u+\left(1-\alpha_{n+1}\right) T\left(x_{n}\right), n \geqslant 0,
$$

where $\left\{\alpha_{n}\right\}$ is a real numbers in $(0,1)$ and $T$ is a nonexpansive mapping of $C$ into itself. Halpern [11] proved that the algorithm (1.4) converges strongly to a fixed point of $\mathrm{T}$ in the framework of Hilbert spaces. Lions [16] and Wittmann [28] improved the result of Halpern by proving strong convergence of $\left\{x_{n}\right\}$ to a fixed point of $T$ under some mild conditions on the real sequence $\left\{\alpha_{n}\right\}$. Reich [24], Shioji and Takahashi [25], and Zegeye and Shahzad [37] extended the result of Wittmann [28] to the case of Banach spaces.

In 2000, Moudafi [21] introduced viscosity approximation method and proved that if $\mathrm{H}$ is a real Hilbert space, then for $x_{0} \in C$, the sequence $\left\{x_{n}\right\}$ generated by the algorithm

$$
x_{n+1}:=\alpha_{n} f\left(x_{n}\right)+\left(1-\alpha_{n}\right) T\left(x_{n}\right), \quad n \geqslant 0,
$$

where $f: C \rightarrow C$ is a contraction mapping and $\left\{\alpha_{n}\right\} \subset(0,1)$ satisfies certain conditions, converges strongly to a fixed point of a nonexpansive mapping T. Moudafi [21] generalized Halpern's theorems in the direction of viscosity approximations. 
Recently, Zegeye [36] introduced Moudafi type approximation method and proved that if $\mathrm{C}$ is a nonempty closed and convex subset of a real Hilbert space $H$ and $T_{i}: C \rightarrow C$ for $i=1,2$ is continuous pseudocontractive mappings such that $\mathcal{F}:=\bigcap_{i=1}^{2} F\left(T_{i}\right) \neq \emptyset$, then for $x_{0} \in C$ the sequence $\left\{x_{n}\right\}$ generated by

$$
x_{n+1}=\alpha_{n} f\left(x_{n}\right)+\left(1-\alpha_{n}\right) T_{r_{n}} F_{r_{n}} x_{n}
$$

where $\left\{\alpha_{n}\right\} \subset[0,1]$ and $\left\{r_{n}\right\} \subset(0, \infty)$ satisfy certain mild conditions and $f$ is a contraction from $C$ into $C$, converges strongly to $z \in \mathcal{F}$. Zegeye's [36] result extends Moudafi [21] result from the class of nonexpansive mappings to the more general class of continuous pseudocontractive mappings. For other related results, we refer to $[2,27,31-35,38]$.

Furthermore, considerable research efforts have been devoted to iterative methods for approximating fixed points of pseudocontractive mappings in Banach spaces (see, e.g., [5, 12, 13, 17, 17, 36, 41]) connected to the class of accretive mappings. However, the analogue of pseudocontractive mapping in Hilbert spaces related to the class of monotone mappings in Banach spaces has not been studied.

It is our purpose in this paper to introduce the class of mappings connected with the class of monotone mappings in Banach spaces which is the analogue of class of pseudocontractive mappings in Hilbert spaces. In addition, we introduce a Halpern-type approximation method for finding a common fixed point of a finite family of the introduced mappings. This provides affirmative answer to the above concern.

\section{Preliminaries}

Let $E$ be a real Banach space. Let $S(E)=\{x \in E:\|x\|=1\}$. Then the norm of $E$ is said to be smooth if

$$
\lim _{t \rightarrow 0} \frac{\|x+t y\|-\|x\|}{t}
$$

exists for each $x, y \in S(E)$. E is called uniformly smooth if the limit (2.1) exists and is attained uniformly for all $(x, y) \in S(E)$. So it is trivial that a uniformly smooth Banach space has a Gâteaux differentiable norm. It is also known that if $E$ is uniformly smooth, then $J$ is uniformly norm to norm continuous on each bounded subset of $E$. Furthermore, if $E$ is a reflexive and strictly convex Banach space with a strictly convex dual, then $\mathrm{J}^{-1}$ is duality mapping from $\mathrm{E}^{*}$ into $\mathrm{E}$ where $\mathrm{JJ}^{-1}=\mathrm{I}_{\mathrm{E}^{*}}$ and $\mathrm{J}^{-1} \mathrm{~J}=\mathrm{I}_{\mathrm{E}}$ (see [26]). We note that in a Hilbert space, $\mathrm{H}$, $\mathrm{J}$ is the identity mapping.

The modulus of convexity of $\mathrm{E}$ is the function $\delta_{\mathrm{E}}:(0,2] \rightarrow[0,1]$ defined by

$$
\delta_{\mathrm{E}}(\epsilon):=\inf \left\{1-\left\|\frac{x+y}{2}\right\|:\|x\|=\|y\|=1 ; \epsilon=\|x-y\|\right\} .
$$

$E$ is called uniformly convex if and only if $\delta_{E}(\epsilon)>0$ for every $\epsilon \in(0,2]$.

Let $E$ be a reflexive, strictly convex, and smooth Banach space and let $C$ be a nonempty closed and convex subset of $E$. Throughout this paper, let the function $\phi: E \times E \rightarrow \mathbb{R}$, introduced by Alber [1], be defined by

$$
\phi(y, x)=\|y\|^{2}-2\langle y, J x\rangle+\|x\|^{2} \text { for } x, y \in E .
$$

We observe that in a Hilbert space $H,(2.2)$ reduces to $\phi(x, y)=\|x-y\|^{2}$ for $x, y \in H$. The generalized projection mapping, introduced by Alber [1], is a mapping $\Pi_{C}: E \rightarrow C$ that assigns an arbitrary point $x \in E$ to the minimizer, $\bar{x}$, of $\phi(., x)$ over $C$, that is, $\Pi_{C} x=\bar{x}$, where $\bar{x}$ is the solution to the minimization problem

$$
\phi(\bar{x}, x)=\min \{\phi(y, x), y \in C\} .
$$

The existence of the solution of this minimization problem is due to Alber [1].

In the sequel, we shall use of the following lemmas. 
Lemma 2.1 ([1]). Let $\mathrm{C}$ be a nonempty closed and convex subset of a real reflexive, strictly convex, and smooth Banach space $\mathrm{E}$ and let $\mathrm{x} \in \mathrm{E}$. Then for all $\mathrm{y} \in \mathrm{C}$,

$$
\phi\left(y, \Pi_{C} x\right)+\phi\left(\Pi_{C} x, x\right) \leqslant \phi(y, x) .
$$

Lemma 2.2 ([15]). Let $\mathrm{E}$ be a real smooth and uniformly convex Banach space and let $\left\{\mathrm{x}_{\mathrm{n}}\right\}$ and $\left\{\mathrm{y}_{\mathrm{n}}\right\}$ be two sequences of $\mathrm{E}$. If either $\left\{x_{n}\right\}$ or $\left\{y_{n}\right\}$ is bounded and $\phi\left(x_{n}, y_{n}\right) \rightarrow 0$ as $n \rightarrow \infty$, then $x_{n}-y_{n} \rightarrow 0$, as $n \rightarrow \infty$.

Lemma 2.3 ([1]). Let $C$ be a convex subset of a real smooth Banach space $E$. Let $x \in E$. Then $x_{0}=\Pi_{C} x$ if and only if

$$
\left\langle z-x_{0}, J x-J x_{0}\right\rangle \leqslant 0, \forall z \in C .
$$

We make use of the function $V: E \times E^{*} \rightarrow \mathbb{R}$ defined by

$$
\mathrm{V}\left(x, x^{*}\right)=\|x\|^{2}-2\left\langle x, x^{*}\right\rangle+\|x\|^{2} \text { for all } x \in E \text { and } x^{*} \in E,
$$

studied by Alber [1]. That is, $V(x, y)=\phi\left(x, J^{-1} x^{*}\right)$ for all $x \in E$ and $x^{*} \in E^{*}$.

We know the following lemma connected to the function $\mathrm{V}$.

Lemma 2.4 ([1]). Let $\mathrm{E}$ be a reflexive strictly convex and smooth Banach space with $\mathrm{E}^{*}$ as its dual. Then

$$
\mathrm{V}\left(x, x^{*}\right)+2\left\langle J^{-1} x^{*}-x, y^{*}\right\rangle \leqslant \mathrm{V}\left(x, x^{*}+y^{*}\right)
$$

for all $\mathrm{x} \in \mathrm{E}$ and $\mathrm{x}^{*}, \mathrm{y}^{*} \in \mathrm{E}^{*}$.

Lemma 2.5 ([3]). Let $\mathrm{C}$ be a nonempty, closed, and convex subset of a smooth, strictly convex, and reflexive real Banach space $\mathrm{E}$. Let $\mathrm{A}: \mathrm{C} \rightarrow \mathrm{E}^{*}$ be a continuous monotone mapping. Then, for $\mathrm{r}>0$ and $\mathrm{x} \in \mathrm{E}$, there exists $z \in \mathrm{C}$ such that

$$
\langle y-z, A z\rangle+\frac{1}{r}\langle y-z, J z-J x\rangle \geqslant 0, \forall y \in C .
$$

Lemma 2.6 ([40]). Let $C$ be a nonempty, closed, and convex subset of a smooth, strictly convex, and reflexive real Banach space $\mathrm{E}$. Let $\mathrm{A}: \mathrm{C} \rightarrow \mathrm{E}^{*}$ be a continuous monotone mapping. For $\mathrm{r}>0$ and $\mathrm{x} \in \mathrm{E}$, define the mapping $\mathrm{F}_{\mathrm{r}}: \mathrm{E} \rightarrow \mathrm{C}$ as follows:

$$
\mathrm{F}_{\mathrm{r}} \mathrm{x}:=\left\{z \in \mathrm{C}:\langle\mathrm{y}-z, A z\rangle+\frac{1}{\mathrm{r}}\langle\mathrm{y}-z, \mathrm{~J} z-\mathrm{Jx}\rangle \geqslant 0, \forall \mathrm{y} \in \mathrm{C}\right\}
$$

for all $x \in \mathrm{E}$. Then the following hold:

(1) $\mathrm{F}_{\mathrm{r}}$ is single-valued;

(2) $\mathrm{F}\left(\mathrm{F}_{\mathrm{r}}\right)=\mathrm{VI}(\mathrm{C}, \mathrm{A})$;

(3) $\phi\left(p, F_{r} x\right)+\phi\left(F_{r} x, x\right) \leqslant \phi(p, x)$ for $p \in F\left(F_{r}\right)$;

(4) $\mathrm{VI}(\mathrm{C}, \mathrm{A})$ is closed and convex.

Lemma 2.7 ([29]). Let $\left\{a_{n}\right\}$ be a sequence of nonnegative real numbers satisfying the following relation:

$$
a_{n+1} \leqslant\left(1-\beta_{n}\right) a_{n}+\beta_{n} \delta_{n}, n \geqslant n_{0},
$$

where $\left\{\beta_{n}\right\} \subset(0,1)$ and $\left\{\delta_{n}\right\} \subset \mathbb{R}$ satisfying the following conditions: $\sum_{n=1}^{\infty} \beta_{n}=\infty$, and $\limsup _{n \rightarrow \infty} \delta_{n} \leqslant 0$. Then, $\lim _{n \rightarrow \infty} a_{n}=0$.

Lemma 2.8 ([18]). Let $\left\{a_{n}\right\}$ be a sequence of real numbers such that there exists a subsequence $\left\{n_{i}\right\}$ of $\{n\}$ such that $a_{n_{i}}<a_{n_{i}+1}$ for all $i \in \mathbb{N}$. Then there exists a nondecreasing sequence $\left\{m_{k}\right\} \subset \mathbb{N}$ such that $m_{k} \rightarrow \infty$ and the following properties are satisfied by all (sufficiently large) numbers $k \in \mathbb{N}$ :

$$
a_{m_{k}} \leqslant a_{m_{k}+1} \text { and } a_{k} \leqslant a_{m_{k}+1} .
$$

In fact, $m_{k}=\max \left\{j \leqslant k: a_{j}<a_{j+1}\right\}$. 


\section{Main result}

Definition 3.1. Let $C$ be a nonempty, closed, and convex subset of a reflexive, strictly convex, and smooth Banach space $\mathrm{E}$. A mapping $\mathrm{T}: \mathrm{C} \rightarrow \mathrm{E}$ is called mono-pseudocontractive if for each $\mathrm{x}, \mathrm{y} \in \mathrm{C}$ we have

$$
\langle x-y, J T x-J T y\rangle \leqslant\langle x-y, J x-J y\rangle \text {. }
$$

Lemma 3.2. Let $\mathrm{C}$ be a nonempty, closed, and convex subset of a reflexive, strictly convex, and smooth Banach space $\mathrm{E}$. Let $\mathrm{T}: \mathrm{C} \rightarrow \mathrm{E}$ be a map. Then $\mathrm{T}$ is psudocontractive if and only if $\mathrm{A}=(\mathrm{J}-\mathrm{JT}): \mathrm{C} \rightarrow \mathrm{E}^{*}$ is monotone. Furthermore, the zero of $\mathrm{A}$ is the fixed point of $\mathrm{T}$.

Proof. Let $x, y \in C$ be arbitrary. Suppose $T$ is mono-pseudocontractive mapping. Then, for $x, y \in C$, we have

$$
\langle A x-A y, x-y,\rangle=\langle(J-J T) x-(J-J T) y, x-y\rangle=\langle J x-J y, x-y\rangle-\langle J T x-J T y, x-y\rangle \geqslant 0 .
$$

Hence, $A$ is monotone. Conversely, suppose $A$ is monotone, we prove that $T$ is mono-pseudocontractive. Let $x, y \in C$. Then,

$$
\langle x-y, J T x-J T y\rangle=\langle x-y,(J-A) x-(J-A) y\rangle=\langle x-y, J x-J y\rangle-\langle x-y, A x-A y\rangle \leqslant\langle x-y, J x-J y\rangle .
$$

Hence, $T$ is mono-pseudocontractive. In addition, we observe that the zero of $A$ is the fixed point of $T$.

Let $g: E \rightarrow(-\infty, \infty]$ be a proper, convex, and lower semicontinuous function. Recall that the subdifferential $\partial \mathrm{g}$ of $\mathrm{g}$ is defined for any $x \in \mathrm{E}$ by

$$
\partial g(x):=\left\{z \in E^{*}:\langle z, y-x\rangle \leqslant g(y)-g(x), \forall y \in E\right\} .
$$

Then $T x:=J^{-1}(J-\partial g)(x)$ is mono-pseudocontractive mapping since the subdifferential $\partial g$ of $g$ is a monotone mapping (see [22, Theorem 2.13, p. 124]). If $E=H$, a real Hilbert space, then $J$ is the identity map on $\mathrm{H}$. Consequently, every pseudocontractive map on $\mathrm{H}$ is mono-pseudocontractive.

A map $\mathrm{T}: \mathrm{C} \rightarrow \mathrm{E}$ is called mono-nonexpansive if

$$
\|x-y\|\|J T x-J T y\| \leqslant\langle x-y, J x-J y\rangle, \forall x, y \in C .
$$

Remark 3.3. We observe that if a map $\mathrm{T}$ is mono-nonexpansive then it is mono-pseudocontractive. In fact,

$$
\langle x-y, J T x-J T y\rangle \leqslant\|x-y\|\|J T x-J T y\| \leqslant\langle x-y, J x-J y\rangle, \forall x, y \in C,
$$

and $\|J T x-J T y\| \leqslant\|J x-J y\|, \forall x, y \in C$.

In the sequel, we shall make use of the following lemmas.

Lemma 3.4. Let $\mathrm{C}$ be a nonempty, closed, and convex subset of a uniformly smooth, and strictly convex real Banach space $\mathrm{E}$. Let $\mathrm{T}: \mathrm{C} \rightarrow \mathrm{E}$ be continuous mono-pseudocontractive mapping. Then, for $\mathrm{r}>0$ and $\mathrm{x} \in \mathrm{E}$, there exists $z \in \mathrm{C}$ such that

$$
\langle y-z, \mathrm{JT} z\rangle-\frac{1}{\mathrm{r}}\langle\mathrm{y}-z,(1+\mathrm{r}) \mathrm{J} z-\mathrm{J} x\rangle \leqslant 0, \forall \mathrm{y} \in \mathrm{C} .
$$

Proof. Let $x \in E$ and $r>0$. Let $A:=J-J T$, where $J$ is the normalized duality mapping. Then, clearly $A$ is continuous monotone mapping. Thus, by Lemma 2.5 there exists $z \in C$ such that $\langle y-z, A z\rangle+\frac{1}{r}\langle y-$ $z, z-x\rangle \geqslant 0$ for all $y \in C$. But this is equivalent to $\langle y-z, J T z\rangle-\frac{1}{r}\langle y-z,(1+r) J z-J x\rangle \leqslant 0$ for all $y \in C$. Hence the lemma holds.

Lemma 3.5. Let $\mathrm{C}$ be a nonempty, closed, and convex subset of a smooth, strictly convex, and reflexive real Banach space $\mathrm{E}$. Let $\mathrm{T}: \mathrm{C} \rightarrow \mathrm{C}$ be continuous mono-pseudocontractive mapping. For $\mathrm{r}>0$ and $\mathrm{x} \in \mathrm{E}$, define a mapping $\mathrm{T}_{\mathrm{r}}: \mathrm{E} \rightarrow \mathrm{C}$ as follows:

$$
\mathrm{T}_{\mathrm{r}} \mathrm{x}:=\left\{z \in \mathrm{C}:\langle\mathrm{y}-z, \mathrm{JT} z\rangle-\frac{1}{\mathrm{r}}\langle\mathrm{y}-z,(1+\mathrm{r}) \mathrm{J} z-\mathrm{J} \mathrm{x}\rangle \leqslant 0, \forall \mathrm{y} \in \mathrm{C}\right\}
$$

for all $\mathrm{x} \in \mathrm{E}$. Then the following hold: 
(1) $\mathrm{T}_{\mathrm{r}}$ is single-valued;

(2) $\phi\left(p, T_{r} x\right)+\phi\left(T_{r} x, x\right) \leqslant \phi(p, x)$ for $p \in F\left(T_{r}\right)$;

(3) $\mathrm{F}\left(\mathrm{T}_{\mathrm{r}}\right)=\mathrm{F}(\mathrm{T})$;

(4) $\mathrm{F}(\mathrm{T})$ is closed and convex.

Proof. We note that $\langle y-z, J T z\rangle-\frac{1}{r}\langle y-z,(1+r) J z-J x\rangle \leqslant 0$ for all $y \in C$ is equivalent to $\langle y-z, A z\rangle+$ $\frac{1}{r}\langle y-z, J z-J x\rangle \geqslant 0$ for all $y \in C$, where $A z:=J z-J T z$ is continuous monotone mapping. Moreover, as $T$ is self-map we have that $\operatorname{VI}(C, A)=F(T)$. Thus, by Lemma 2.6 the conclusions of (1)-(4) hold.

Let $\mathrm{C}$ be a nonempty, closed, and convex subset of a smooth, strictly convex, and reflexive real Banach space $E$. Let $T_{i}: C \rightarrow C$ for $i=1,2$ be continuous mono-pseudocontractive mappings. Then in what follows, $T_{r_{n}}, F_{r_{n}}: E \rightarrow C$ are defied as follows: for $x \in E$ and $\left\{r_{n}\right\} \subset(0, \infty)$, define

$$
\mathrm{T}_{1, \mathrm{r}_{\mathrm{n}}} x:=\left\{z \in \mathrm{C}:\left\langle\mathrm{y}-z, \mathrm{JT}_{1} z\right\rangle-\frac{1}{\mathrm{r}_{\mathrm{n}}}\left\langle\mathrm{y}-z,\left(1+\mathrm{r}_{\mathrm{n}}\right) \mathrm{J} z-\mathrm{Jx}\right\rangle \leqslant 0, \forall \mathrm{y} \in \mathrm{C}\right\}
$$

and

$$
\mathrm{T}_{2, r_{\mathrm{n}}} x:=\left\{z \in \mathrm{C}:\left\langle\mathrm{y}-z, \mathrm{JT}_{2} z\right\rangle-\frac{1}{\mathrm{r}_{\mathrm{n}}}\left\langle\mathrm{y}-z,\left(1+\mathrm{r}_{\mathrm{n}}\right) \mathrm{J} z-\mathrm{Jx}\right\rangle \leqslant 0, \forall \mathrm{y} \in \mathrm{C}\right\} .
$$

Then in what follows, we shall study the following iteration process:

$$
\left\{\begin{array}{l}
u, x_{0} \in C \text { chosen arbitrarily, } \\
x_{n+1}=J^{-1}\left(\alpha_{n} J u+\left(1-\alpha_{n}\right) J T_{2, r_{n}} T_{1, r_{n}} x_{n}\right),
\end{array}\right.
$$

where $J$ is the normalized duality mapping on $E ; \alpha_{n} \in(0,1)$ satisfies $\lim _{n \rightarrow \infty} \alpha_{n}=0$ and $\sum_{n=1}^{\infty} \alpha_{n}=\infty$; $\left\{r_{n}\right\} \subset\left[c_{1}, \infty\right)$ for some $c_{1}>0$ and for all $n \in \mathbb{N}$.

Now, we prove our main convergence theorem.

Theorem 3.6. Let $\mathrm{C}$ be a nonempty, closed, and convex subset of a uniformly smooth, and uniformly convex real Banach space $\mathrm{E}$. Let $\mathrm{T}_{1}, \mathrm{~T}_{2}: \mathrm{C} \rightarrow \mathrm{C}$ be continuous mono-pseudocontractive mappings with $\mathcal{F}:=\bigcap_{i=1}^{2} \mathrm{~F}\left(\mathrm{~T}_{\mathrm{i}}\right) \neq \emptyset$. Let $\left\{x_{n}\right\}_{n} \geqslant 0$ be a sequence defined by (3.1). Then, the sequence $\left\{x_{n}\right\}_{\mathfrak{n} \geqslant 0}$ converges strongly to $\Pi_{\mathcal{F}}(u)$, where $\Pi_{\mathcal{F}}$ is the generalized projection from $\mathrm{E}$ onto $\mathcal{F}$.

Proof. Since by Lemma 3.5 we have $\mathcal{F}$ is nonempty closed and convex we can take $x^{*}:=\Pi_{\mathcal{F}} \mathfrak{u}$. Let $u_{n}=T_{1, r_{n}} x_{n}$ and $w_{n}=T_{2, r_{n}} u_{n}$. Now from (3.1), Lemma 2.1, and property of $\phi$ we get that

$$
\begin{aligned}
\phi\left(x^{*}, x_{n+1}\right) & =\phi\left(x^{*}, J^{-1}\left(\alpha_{n} J u+\left(1-\alpha_{n}\right) J w_{n}\right)\right) \\
& =\left\|x^{*}\right\|^{2}-2\left\langle x^{*}, \alpha_{n} J u+\left(1-\alpha_{n}\right) J w_{n}\right\rangle+\left\|\alpha_{n} J u+\left(1-\alpha_{n}\right) J w_{n}\right\|^{2} \\
& \leqslant\left\|x^{*}\right\|^{2}-2 \alpha_{n}\left\langle x^{*}, J u\right\rangle-2\left(1-\alpha_{n}\right)\left\langle x^{*}, J w_{n}\right\rangle+\alpha_{n}\|J u\|^{2}+\left(1-\alpha_{n}\right)\left\|J w_{n}\right\|^{2} \\
& =\alpha_{n} \phi\left(x^{*}, u\right)+\left(1-\alpha_{n}\right) \phi\left(x^{*}, w_{n}\right) \\
& =\alpha_{n} \phi\left(x^{*}, u\right)+\left(1-\alpha_{n}\right) \phi\left(x^{*}, T_{2, r_{n}} u_{n}\right) \\
& \leqslant \alpha_{n} \phi\left(x^{*}, u\right)+\left(1-\alpha_{n}\right) \phi\left(x^{*}, u_{n}\right) \\
& \leqslant \alpha_{n} \phi\left(x^{*}, u\right)+\left(1-\alpha_{n}\right) \phi\left(x^{*}, x_{n}\right) .
\end{aligned}
$$

Then, by induction we get that

$$
\phi\left(x^{*}, x_{n+1}\right) \leqslant \max \left\{\phi\left(x^{*}, x_{n}\right), \phi\left(x^{*}, u\right)\right\}, \forall n \geqslant 1,
$$

and hence $\left\{x_{n}\right\},\left\{u_{n}\right\}$, and $\left\{w_{n}\right\}$ are bounded. Now, by Lemmas 2.1, 2.4, and 2.6 (3) we get

$$
\phi\left(x^{*}, x_{n+1}\right)=V\left(x^{*}, \alpha_{n} u+\left(1-\alpha_{n}\right) J w_{n}\right)
$$




$$
\begin{aligned}
& \leqslant V\left(x^{*}, J x_{n+1}-\alpha_{n}\left(J u-J x^{*}\right)\right)-2\left\langle x_{n+1}-x^{*},-\alpha_{n}\left(J u-J x^{*}\right)\right\rangle \\
& =\phi\left(x^{*}, J^{-1}\left(\alpha_{n} J x^{*}+\left(1-\alpha_{n}\right) J w_{n}\right)\right)+2 \alpha_{n}\left\langle x_{n+1}-x^{*}, J u-J x^{*}\right\rangle \\
& \leqslant \alpha_{n} \phi\left(x^{*}, x^{*}\right)+\left(1-\alpha_{n}\right) \phi\left(x^{*}, w_{n}\right)+2 \alpha_{n}\left\langle x_{n+1}-x^{*}, J u-J x^{*}\right\rangle \\
& \leqslant\left(1-\alpha_{n}\right)\left[\phi\left(x^{*}, u_{n}\right)-\phi\left(w_{n}, u_{n}\right)\right]+2 \alpha_{n}\left\langle x_{n+1}-x^{*}, J u-J x^{*}\right\rangle \\
& =\left(1-\alpha_{n}\right) \phi\left(x^{*}, u_{n}\right)-\left(1-\alpha_{n}\right) \phi\left(u_{n}, w_{n}\right)+2 \alpha_{n}\left\langle x_{n+1}-x^{*}, J u-J x^{*}\right\rangle \\
& \leqslant\left(1-\alpha_{n}\right)\left[\phi\left(x^{*}, x_{n}\right)-\phi\left(u_{n}, x_{n}\right)\right]-\left(1-\alpha_{n}\right) \phi\left(w_{n}, u_{n}\right)+2 \alpha_{n}\left\langle x_{n+1}-x^{*}, J u-J x^{*}\right\rangle \\
& =\left(1-\alpha_{n}\right) \phi\left(x^{*}, x_{n}\right)-\left(1-\alpha_{n}\right)\left[\phi\left(u_{n}, x_{n}\right)+\phi\left(w_{n}, u_{n}\right)\right]+2 \alpha_{n}\left\langle x_{n+1}-x^{*}, J u-J x^{*}\right\rangle \\
& \leqslant\left(1-\alpha_{n}\right) \phi\left(x^{*}, x_{n}\right)+2 \alpha_{n}\left\langle x_{n}-x^{*}, J u-J x^{*}\right\rangle+2 \alpha_{n}\left\|x_{n+1}-x_{n} \mid\right\| J u-J x^{*} \| .
\end{aligned}
$$

Now, we consider two possible cases on $\phi\left(x^{*}, x_{n}\right)$.

Case 1. Suppose that there exists $n_{0} \in \mathbb{N}$ such that $\left\{\phi\left(x^{*}, x_{n}\right)\right\}$ is decreasing. Then, we obtain that $\left\{\phi\left(x^{*}, x_{n}\right)\right\}$ is convergent. Thus, from (3.2) we get that $\phi\left(w_{n}, u_{n}\right), \phi\left(u_{n}, x_{n}\right) \rightarrow 0$ and hence by Lemma 2.2 we obtain that

$$
w_{n}-u_{n} \rightarrow 0, u_{n}-x_{n} \rightarrow 0, \text { as } n \rightarrow \infty .
$$

Furthermore, from the property of $\phi$ and the fact that $\alpha_{n} \rightarrow 0$, as $n \rightarrow \infty$ we have that

$$
\begin{aligned}
\phi\left(w_{n}, x_{n+1}\right) & =\phi\left(w_{n}, J^{-1}\left(\alpha_{n} J u+\left(1-\alpha_{n}\right) J w_{n}\right)\right) \\
& \leqslant \alpha_{n} \phi\left(w_{n}, u\right)+\left(1-\alpha_{n}\right) \phi\left(w_{n}, w_{n}\right) \leqslant \alpha_{n} \phi\left(w_{n}, u\right)+\left(1-\alpha_{n}\right) \phi\left(w_{n}, w_{n}\right) \rightarrow 0 \text { as } n \rightarrow \infty,
\end{aligned}
$$

and hence from Lemma 2.2 we get that $w_{n}-x_{n+1} \rightarrow 0$ and this with (3.4) give that

$$
x_{n}-x_{n+1} \rightarrow 0 \text { as } n \rightarrow \infty .
$$

Since $\left\{x_{n}\right\}$ is bounded and $E$ is reflexive, we choose a subsequence $\left\{x_{n_{i}}\right\}$ of $\left\{x_{n}\right\}$ such that $x_{n_{i}} \rightarrow z$ and $\limsup _{n \rightarrow \infty}\left\langle x_{n}-x^{*}, J u-J x^{*}\right\rangle=\lim _{i \rightarrow \infty}\left\langle x_{n_{i}}-x^{*}, J u-J x^{*}\right\rangle$. Then from (3.5) and (3.4) we get that $u_{n_{i}} \rightarrow z$ and $w_{n_{i}}^{n \rightarrow \infty} \rightarrow$.

Now, we show that $z \in F\left(T_{1}\right)$. But from the definition of $u_{n}$ we have that

$$
\left\langle y-u_{n}, J T_{1} u_{n}\right\rangle-\left\langle y-u_{n}, \frac{\left(1+r_{n}\right) J u_{n}-J x_{n}}{r_{n}}\right\rangle \leqslant 0, \forall y \in C,
$$

and hence

$$
-\left\langle y-u_{n_{i}}, J T_{1} u_{n_{i}}\right\rangle+\left\langle y-u_{n_{i}}, \frac{\left(1+r_{n_{i}}\right) J u_{n_{i}}-J x_{n_{i}}}{r_{n_{i}}}\right\rangle \geqslant 0, \forall y \in C,
$$

which implies that

$$
\left\langle y-u_{n_{i}}, J u_{n_{i}}-J T_{1} u_{n_{i}}\right\rangle+\left\langle y-u_{n_{i}}, \frac{J u_{n_{i}}-J x_{n_{i}}}{r_{n_{i}}}\right\rangle \geqslant 0, \forall y \in C .
$$

Set $v_{\mathrm{t}}=\mathrm{t} \mathrm{y}+(1-\mathrm{t}) z$ for all $\mathrm{t} \in(0,1]$ and $y \in \mathrm{C}$. Then, we get that $v_{\mathrm{t}} \in \mathrm{C}$. Now, from (3.6) it follows that

$$
\begin{aligned}
\left\langle v_{t}-u_{n_{i}}, J v_{t}-J T_{1} v_{t}\right\rangle & \geqslant\left\langle v_{t}-u_{n_{i}}, J v_{t}-J T_{1} v_{t}\right\rangle-\left\langle v_{t}-u_{n_{i}}, J u_{n_{i}}-J T_{1} u_{n_{i}}\right\rangle-\left\langle v_{t}-u_{n_{i}}, \frac{J u_{n_{i}}-J x_{n_{i}}}{r_{n_{i}}}\right\rangle \\
& =\left\langle v_{t}-u_{n_{i}}, J v_{t}-J u_{n_{i}}\right\rangle-\left\langle v_{t}-u_{n_{i}}, \frac{J u_{n_{i}}-J x_{n_{i}}}{r_{n_{i}}}\right\rangle
\end{aligned}
$$

Furthermore, the mono-pseudocontractivity nature of $T_{1}$ gives that $\left\langle v_{t}-u_{n_{i}},\left(J v_{t}-J T_{1} v_{t}\right)-\left(J u_{n_{i}}-\right.\right.$ $\left.\left.J T_{1} u_{n_{i}}\right)\right\rangle \geqslant 0$ and the uniform continuity of $J$ with (3.4) imply that $J u_{n_{i}}-J x_{n_{i}} \rightarrow 0$ as $i \rightarrow \infty$. Thus, it follows that

$$
0 \leqslant \lim _{i \rightarrow \infty}\left\langle v_{t}-u_{n_{i}}, J v_{t}-J T_{1} v_{t}\right\rangle=\left\langle v_{t}-z, J v_{t}-J T_{1} v_{t}\right\rangle
$$


and hence

$$
\left\langle\mathrm{y}-z, \mathrm{~J}_{\mathrm{t}}-\mathrm{JT}_{1} v_{\mathrm{t}}\right\rangle \geqslant 0, \forall \mathrm{y} \in \mathrm{C} .
$$

If $t \rightarrow 0$, the continuity of $T_{1}$ and $J$ imply that

$$
\left\langle\mathrm{y}-z, \mathrm{~J} z-\mathrm{JT}_{1} z\right\rangle \geqslant 0, \forall \mathrm{y} \in \mathrm{C} .
$$

Now, considering $y=\mathrm{T}_{1} z$ we obtain that $\left\langle\mathrm{T}_{1} z-z, \mathrm{JT}_{1} z-\mathrm{J} z\right\rangle \leqslant 0$ and hence monotonicity of $\mathrm{J}$ implies that

$$
\left\langle\mathrm{y}-\mathrm{z}, \mathrm{J} z-\mathrm{JT}_{1} z\right\rangle=0, \forall \mathrm{y} \in \mathrm{C} .
$$

Thus, the strict convexity of $\mathrm{E}$ gives that $\mathrm{T}_{1} z=z$ and hence $z \in \mathrm{F}\left(\mathrm{T}_{1}\right)$.

Similarly, considering the definition of $w_{n}$ we get that $z \in \mathrm{F}\left(\mathrm{T}_{2}\right)$. Therefore, we have that $z \in \mathrm{F}\left(\mathrm{T}_{1}\right) \cap$ $\mathrm{F}\left(\mathrm{T}_{2}\right)$. Thus, by Lemma 2.3, we immediately obtain that $\lim \sup \left\langle x_{\mathrm{n}}-x^{*}, J u-J x^{*}\right\rangle=\left\langle z-x^{*}, J u-J x^{*}\right\rangle \leqslant 0$. It follows from Lemma 2.7 and (3.3) that $\phi\left(x^{*}, x_{n}\right) \rightarrow 0$ as $n \rightarrow \infty$. Consequently, $x_{n} \rightarrow x^{*}$.

Case 2. Suppose that there exists a subsequence $\left\{n_{i}\right\}$ of $\{n\}$ such that

$$
\phi\left(x^{*}, x_{n_{i}}\right)<\phi\left(x^{*}, u_{n_{i}+1}\right)
$$

for all $i \in \mathbb{N}$. Then by Lemma 2.8, there exists a nondecreasing sequence $\left\{m_{k}\right\} \subset \mathbb{N}$ such that $m_{k} \rightarrow \infty$, $\phi\left(x^{*}, x_{m_{k}}\right) \leqslant \phi\left(x^{*}, x_{m_{k}+1}\right)$ and $\phi\left(x^{*}, x_{k}\right) \leqslant \phi\left(x^{*}, x_{m_{k}+1}\right)$ for all $k \in \mathbb{N}$. Thus, from (3.2) and the fact that $\alpha_{n} \rightarrow 0$ we obtain

$$
\begin{aligned}
\left(1-\alpha_{m_{k}}\right)( & \left.\phi\left(u_{m_{k}}, x_{m_{k}}\right)+\phi\left(w_{m_{k}}, u_{m_{k}}\right)\right) \\
\leqslant & \left(\phi\left(x^{*}, x_{m_{k}}\right)-\phi\left(x^{*}, x_{m_{k}+1}\right)\right)+\alpha_{m_{k}} \phi\left(x^{*}, x_{m_{k}}\right) \\
& +2 \alpha_{m_{k}}\left\langle x_{m_{k}}-x^{*}, J u-J x^{*}\right\rangle+2 \alpha_{m_{k}}\left\|x_{m_{k}}-x_{m_{k}+1}\right\|\left\|J u-J x^{*}\right\| \rightarrow 0
\end{aligned}
$$

as $k \rightarrow \infty$. But this implies that $\phi\left(u_{m_{k}}, x_{m_{k}}\right), \phi\left(w_{m_{k}}, u_{m_{k}}\right) \rightarrow 0$ as $k \rightarrow \infty$. Thus, following the method in Case 1, we obtain that

$$
\limsup _{k \rightarrow \infty}\left\langle x_{m_{k}}-x^{*}, J u-J x^{*}\right\rangle \leqslant 0 .
$$

In addition, from (3.3) we have that

$$
\phi\left(x^{*}, x_{m_{k}+1}\right) \leqslant\left(1-\alpha_{m_{k}}\right) \phi\left(x^{*}, x_{m_{k}}\right)+2 \alpha_{m_{k}}\left\langle x_{m_{k}}-x^{*}, J u-J x^{*}\right\rangle+2 \alpha_{m_{k}}\left\|x_{m_{k}}-x_{m_{k}+1}\left|\left\|\mid J u-J x^{*}\right\|,\right.\right.
$$

which implies that

$$
\begin{aligned}
\alpha_{m_{k}} \phi\left(x^{*}, x_{m_{k}}\right) & \leqslant \phi\left(x^{*}, x_{m_{k}}\right)-\phi\left(x^{*}, x_{m_{k}+1}\right)+2 \alpha_{m_{k}}\left\langle x_{m_{k}}-x^{*}, J u-J x^{*}\right\rangle \\
& \leqslant 2 \alpha_{m_{k}}\left\langle x_{m_{k}}-x^{*}, J u-J x^{*}\right\rangle+2 \alpha_{m_{k}}\left\|x_{m_{k}}-x_{m_{k}+1}\right\|\left\|J u-J x^{*}\right\| .
\end{aligned}
$$

Furthermore, since $\alpha_{m_{k}}>0$, inequality (3.9) gives that

$$
\phi\left(x^{*}, x_{m_{k}}\right) \leqslant 2\left\langle z_{m_{k}}-x^{*}, J u-J x^{*}\right\rangle+2\left\|x_{m_{k}}-x_{m_{k}+1}\left|\left\|\mid J u-J x^{*}\right\| .\right.\right.
$$

Then it follows from (3.7) and (3.5) that $\phi\left(x^{*}, x_{m_{k}}\right) \rightarrow 0$, as $k \rightarrow \infty$. This together with (3.8) implies that $\phi\left(x^{*}, x_{m_{k}+1}\right) \rightarrow 0$. Thus, since $\phi\left(x^{*}, x_{k}\right) \leqslant \phi\left(x^{*}, x_{m_{k}+1}\right)$ for all $k \in \mathbb{N}$, we conclude that $x_{k} \rightarrow x^{*}$, as $k \rightarrow \infty$. Therefore, from Cases 1 and 2 we conclude that $\left\{x_{n}\right\}$ converges strongly to $x^{*}=\Pi_{F} u$ and the proof is complete.

If in Theorem 3.6, we assume that $T_{2} \equiv I$, the identity mapping on $C$, then we obtain the following corollary. 
Corollary 3.7. Let $\mathrm{C}$ be a nonempty, closed, and convex subset of a uniformly smooth, and uniformly convex real Banach space $\mathrm{E}$. Let $\mathrm{T}: \mathrm{C} \rightarrow \mathrm{C}$ be continuous mono-pseudocontractive mapping with $\mathrm{F}(\mathrm{T}) \neq \emptyset$. Let $\left\{x_{\mathrm{n}}\right\}_{\mathrm{n}} \geqslant 0$ be a sequence defined by:

$$
\left\{\begin{array}{l}
u, x_{0} \in C \text { chosen arbitrarily, } \\
x_{n+1}=J^{-1}\left(\alpha_{n} J u+\left(1-\alpha_{n}\right) \mathrm{JT}_{r_{n}} x_{n}\right),
\end{array}\right.
$$

where $\mathrm{T}_{\mathrm{r}} \mathrm{x}:=\left\{z \in \mathrm{C}:\langle\mathrm{y}-z, \mathrm{JT} z\rangle-\frac{1}{\mathrm{r}}\langle\mathrm{y}-z,(1+\mathrm{r}) \mathrm{J} z-\mathrm{Jx}\rangle \leqslant 0, \forall \mathrm{y} \in \mathrm{C}\right\}$, for all $\mathrm{x} \in \mathrm{E} ; \mathrm{J}$ is the normalized duality mapping on $E ; \alpha_{n} \in(0,1)$ satisfying $\lim _{n \rightarrow \infty} \alpha_{n}=0$ and $\sum_{n=1}^{\infty} \alpha_{n}=\infty$ and $\left\{\gamma_{n}\right\} \subset\left[c_{1}, \infty\right)$, for some $c_{1}>0$. Then, the sequence $\left\{x_{n}\right\}_{n} \geqslant 0$ converges strongly to $x^{*}=\Pi_{\mathrm{F}} u$.

Proof. Put $\mathrm{T}:=\mathrm{T}_{1}$ and $\mathrm{T}_{2}=\mathrm{I}$, the identity mapping on $\mathrm{C}$ in Theorem 3.6. Then scheme (3.1) reduces to (3.10). Therefore, the conclusion follows from Theorem 3.6.

If $\mathrm{E}=\mathrm{H}$, a real Hilbert space, we have that $\mathrm{E}$ is uniformly smooth and uniformly convex; $\mathrm{J}=\mathrm{I}$, the identity operator on $\mathrm{H}$. Thus, for $r>0$, if we define

$$
\mathrm{T}_{i, r} x:=\left\{z \in \mathrm{C}:\left\langle\mathrm{y}-z, \mathrm{~T}_{\mathrm{i}} z\right\rangle-\frac{1}{\mathrm{r}}\langle\mathrm{y}-z,(1+\mathrm{r}) z-\mathrm{x}\rangle \leqslant 0, \forall \mathrm{y} \in \mathrm{C}\right\}
$$

for all $x \in E$ and $i=1,2$ then mono-pseudocontractive mappings reduce to pseudocontractive mappings. Thus, the following corollary follows.

Corollary 3.8. Let $\mathrm{C}$ be a nonempty, closed, and convex subset of a real Hilbert space $\mathrm{H}$. Let $\mathrm{T}_{1}, \mathrm{~T}_{2}: \mathrm{C} \rightarrow \mathrm{C}$ be continuous mono-nonexpansive mappings. Let $\mathcal{F}:=\bigcap_{i=1}^{2} \mathrm{~F}\left(\mathrm{~T}_{i}\right) \neq \emptyset$. Let $\left\{x_{n}\right\}_{n} \geqslant 0$ be a sequence defined by:

$$
\left\{\begin{array}{l}
u, x_{0} \in C \text { chosen arbitrarily, } \\
x_{n+1}=\alpha_{n} u+\left(1-\alpha_{n}\right) T_{2, r_{n}} T_{1, r_{n}} x_{n}
\end{array}\right.
$$

where $T_{1, r}, T_{2, r}$ are as in (3.11), $\alpha_{n} \in(0,1)$ satisfying $\lim _{n \rightarrow \infty} \alpha_{n}=0$ and $\sum_{n=1}^{\infty} \alpha_{n}=\infty$, and $\left\{r_{n}\right\} \subset\left[c_{1}, \infty\right)$, for some $\mathrm{c}_{1}>0$. Then, the sequence $\left\{x_{n}\right\}$ converges strongly to $x^{*}=\Pi_{\mathrm{F}} u$.

If $T_{1}$ and $T_{2}$, are mono-nonexpansive mappings, then they are mono-pseudocontractive mappings and hence, we get the following corollary.

Corollary 3.9. Let $\mathrm{C}$ be a nonempty, closed and, convex subset of a uniformly smooth, and uniformly convex real Banach space $\mathrm{E}$. Let $\mathrm{T}_{1}, \mathrm{~T}_{2}: \mathrm{C} \rightarrow \mathrm{C}$ be continuous mono-nonexpansive mappings. Let $\mathcal{F}:=\bigcap_{i=1}^{2} \mathrm{~F}\left(\mathrm{~T}_{i}\right) \neq \emptyset$. Let $\left\{x_{n}\right\}_{n} \geqslant 0$ be a sequence defined by:

$$
\left\{\begin{array}{l}
u, x_{0} \in C \text { chosen arbitrarily, } \\
\left.x_{n+1}=J^{-1}\left(\alpha_{n}\right) u+\left(1-\alpha_{n}\right) J T_{2, r_{n}} T_{1, r_{n}} x_{n}\right),
\end{array}\right.
$$

where $T_{1, r}, T_{2, r}$ are as in (3.11), $\alpha_{n} \in(0,1)$ satisfying $\lim _{n \rightarrow \infty} \alpha_{n}=0$ and $\sum_{n=1}^{\infty} \alpha_{n}=\infty$, and $\left\{r_{n}\right\} \subset\left[c_{1}, \infty\right)$, for some $\mathrm{c}_{1}>0$. Then, the sequence $\left\{\mathrm{x}_{\mathrm{n}}\right\}$ converges strongly to $\mathrm{x}^{*}=\Pi_{\mathrm{F}} \mathrm{u}$.

The proof of the following theorem for a common fixed point of a finite family of continuous monopseudocontractive can be easily obtained from the method of proof of Theorem 3.6.

Theorem 3.10. Let $\mathrm{C}$ be a nonempty, closed, and convex subset of a uniformly smooth, and uniformly convex real Banach space $\mathrm{E}$. Let $\mathrm{T}_{\mathrm{k}}, \mathrm{C} \rightarrow \mathrm{C}, \mathrm{k}=1,2, \ldots, \mathrm{m}$ be finite family of continuous mono-pseudocontractive mappings. Let $\mathrm{F}:=\bigcap_{\mathrm{k}=1}^{\mathrm{m}} \mathrm{F}\left(\mathrm{T}_{\mathrm{k}}\right) \neq \emptyset$. Let $\left\{\mathrm{x}_{\mathrm{n}}\right\}_{\mathrm{n} \geqslant 0}$ be a sequence defined by

$$
\left\{\begin{array}{l}
u, x_{0} \in C, \text { chosen arbitrarily, } \\
w_{1, n}=\mathrm{T}_{1, r_{n}} x_{n} ; w_{2, n}=T_{2, r_{n}} w_{1, n} ; \ldots ; w_{m, n}=T_{m, r_{n}} w_{m-1, n} \\
x_{n+1}=J^{-1}\left(\alpha_{n} J u+\left(1-\alpha_{n}\right) J w_{m, n}\right)
\end{array}\right.
$$


where $\alpha_{n} \in(0,1)$ satisfying $\lim _{n \rightarrow \infty} \alpha_{n}=0$ and $\sum_{n=1}^{\infty} \alpha_{n}=\infty$ and $\left\{r_{n}\right\} \subset\left[c_{1}, \infty\right)$ for some $c_{1}>0$. Then, the sequence $\left\{x_{n}\right\}$ converges strongly to $x^{*}=\Pi_{\mathrm{F}} u$.

We also note that the method of proof of Theorem 3.6 provides the following theorem for approximating the minimum-norm point of a common fixed points of two mono-pseudocontractive mappings.

Theorem 3.11. Let $\mathrm{C}$ be a nonempty, closed, and convex subset of a uniformly smooth, and uniformly convex real Banach space $\mathrm{E}$. Let $\mathrm{T}_{1}, \mathrm{~T}_{2}: \mathrm{C} \rightarrow \mathrm{C}$ be continuous mono-pseudocontractive mappings with $\mathcal{F}:=\bigcap_{i=1}^{2} \mathrm{~F}\left(\mathrm{~T}_{i}\right) \neq \emptyset$. Let $\left\{x_{n}\right\}_{n} \geqslant 0$ be a sequence defined by

$$
\left\{\begin{array}{l}
x_{0} \in C, \text { chosen arbitrarily, } \\
x_{n+1}=\left(1-\alpha_{n}\right) T_{2, r_{n}} T_{1, r_{n}} x_{n}
\end{array}\right.
$$

Then, the sequence $\left\{x_{n}\right\}_{n} \geqslant 0$ converges strongly to $x^{*}=\Pi_{\mathcal{F}}(0)$, the minimum-norm $x^{*}$ of $\mathcal{F}$ with respect to the Lyapunov function $\phi$.

\section{Numerical example}

In this section, we give an example of two continuous mono-pseudocontractive mappings with all the conditions of Theorem 3.6 and some numerical experiment result to explain the conclusion of the theorem.

Example 4.1. Let $H=\mathbb{R}$ with Euclidean norm. Let $C=[-1,10]$ and $T_{1}: C \rightarrow \mathbb{R}$ be defined by

$$
\mathrm{T}_{1} x:= \begin{cases}-4 x-\frac{3}{2}, & x \in\left[-1, \frac{-1}{2}\right), \\ x, & x \in\left[\frac{-1}{2}, 10\right] .\end{cases}
$$

Then, we see that $I-T_{1}$ is continuous monotone and hence $T_{1}$ is continuous mono-pseudocontractive mapping on $C$ with $F\left(T_{1}\right)=\left[\frac{-1}{2}, 10\right]$. In addition, if $x \in\left[-1,-\frac{1}{2}\right)$, assuming that $z \in\left[-1,-\frac{1}{2}\right)$ we have that

$$
\left\langle y-z, T_{1} z\right\rangle-\frac{1}{r}\langle y-z,(1+r) z-x\rangle \leqslant 0, \forall y \in C,
$$

is equivalent to

$$
\left[(1+r) z-x+\left(4 z r+\frac{3}{2} r\right)\right] y \geqslant\left[(1+r) z-x+\left(4 r z+\frac{3}{2} r\right)\right] z, \quad \forall y \in C
$$

But this holds, if $z=\frac{x-\frac{3 r}{2}}{1+5 r}$.

If $x \in\left[-\frac{1}{2}, 10\right]$, considering $z \in\left[-\frac{1}{2}, 10\right]$, we get that

$$
\left\langle y-z, T_{1} z\right\rangle-\frac{1}{r}\langle y-z,(1+r) z-x\rangle \leqslant 0, \quad \forall y \in C,
$$

is equivalent to $(y-z) z-\frac{1}{r}(y-z)[(1+r) z-x] \leqslant 0$ for all $y \in C$, which is equivalent to $(z-x) y \geqslant(z-x) z$ for all $y \in C$. But this holds, if $z=x$. Therefore, we get that

$$
\mathrm{T}_{1, \mathrm{r}} \mathrm{x}:= \begin{cases}\frac{x-\frac{3 \mathrm{r}}{2}}{1+5 \mathrm{r}}, & x \in\left[-1,-\frac{1}{2}\right) \\ x, & x \in\left[-\frac{1}{2}, 10\right]\end{cases}
$$

Now, let $T_{2}: C \rightarrow \mathbb{R}$ be defined by

$$
\mathrm{T}_{2} x:= \begin{cases}x, & x \in[-1,1) \\ x-\frac{1}{8}(x-1)^{2}, & x \in[1,10]\end{cases}
$$


Then, we see that $I-T_{2}$ is continuous monotone and hence $T_{2}$ is continuous mono-pseudocontractive on C with $F\left(T_{2}\right)=[-1,1]$. In addition, if $x \in[-1,1]$, considering $z \in[-1,1]$, we get that

$$
\left\langle y-z, T_{2} z\right\rangle-\frac{1}{r}\langle y-z,(1+r) z-x\rangle \leqslant 0, \forall y \in C,
$$

is equivalent to $(y-z) z-\frac{1}{r}(y-z)[(1+r) z-x] \leqslant 0$ for all $y \in C$, which is equivalent to $(z-x) y \geqslant(z-x) z$ for all $y \in C$. But this holds, if $z=x$.

If $x \in[1,10]$, assuming that $z \in[1,10]$ we have that

$$
\left\langle y-z, T_{2} z\right\rangle-\frac{1}{r}\langle y-z,(1+r) z-x\rangle \leqslant 0, \forall y \in C,
$$

is equivalent to

$$
(y-z)\left[(1+r) z-x-z r+\frac{r}{8}(z-1)^{2}\right] \geqslant 0, \forall y \in C .
$$

But this holds, if $(1+r) z-x-z r+\frac{r}{8}(z-1)^{2}=0$ or $z=\frac{1}{2 r}(2 r-8)+\frac{1}{2 r} \sqrt{64+32 r(x-1)}$. Therefore, we get that

$$
\mathrm{T}_{2, \mathrm{r}} \mathrm{x}:= \begin{cases}x, & x \in[-1,1), \\ \frac{1}{2 \mathrm{r}}(2 \mathrm{r}-8)+\frac{1}{2 \mathrm{r}} \sqrt{64+32 \mathrm{r}(x-1)}, & x \in[1,10] .\end{cases}
$$

It is also clear that $\mathrm{F}\left(\mathrm{T}_{1}\right) \cap \mathrm{F}\left(\mathrm{T}_{2}\right)=\left[-\frac{1}{2}, 10\right] \cap[-1,1]=\left[-\frac{1}{2}, 1\right]$.

Now, if we take, $\alpha_{n}=\frac{1}{n+100}, r_{n}=10$ for all $n \geqslant 1$, and $u \in C$, we observe that the conditions of Theorem 3.6 are satisfied and scheme (3.1) reduces to

$$
\left\{\begin{array}{l}
u, x_{0} \in C \text { chosen arbitrarily, } \\
x_{n+1}=\alpha_{n} u+\left(1-\alpha_{n}\right) T_{2, r_{n}} T_{1, r_{n}} x_{n}
\end{array}\right.
$$

Thus, if $u=2$ and $x_{0}=3$, the scheme (4.1) converges strongly to $1.0=P_{\mathcal{F}}(u)$ and if $u=0.5$ and $x_{0}=-1$ the scheme (4.1) converges strongly to $0.5=\mathrm{P}_{\mathcal{F}}(\mathrm{u})$ (see Figure 1 below).

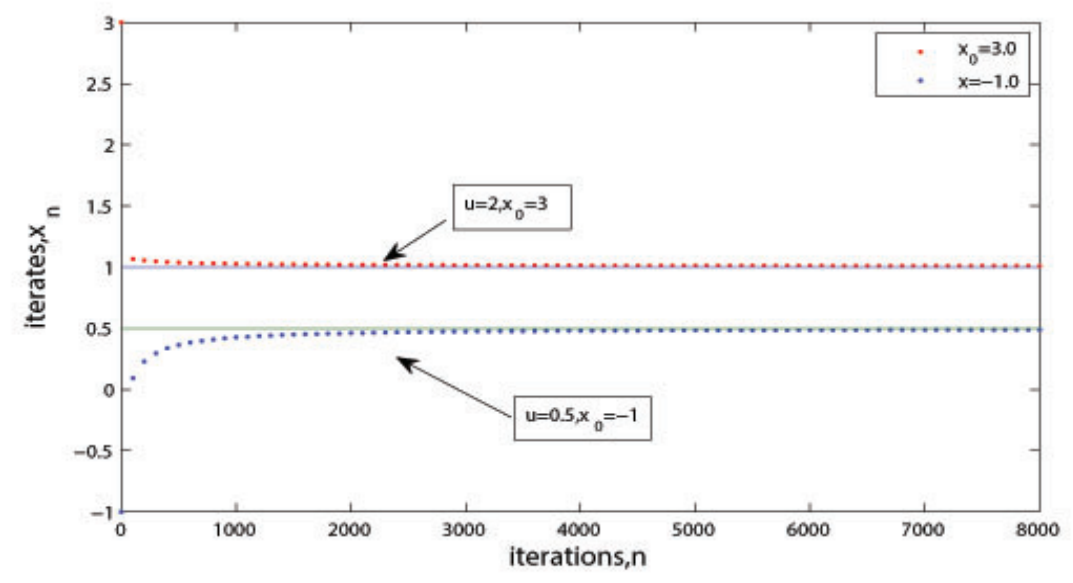

Figure 1: Convergence of $x_{n}$ with initial values $u=2, x_{0}=3$ and $u=0.5, x_{0}=-1$

Remark 4.2. Definition 3.1 introduces a class of mono-pseudocontractive mappings which is very much related to the class of monotone mappings in Banach spaces.

Remark 4.3. Theorem 3.6 provides strong convergence theorem for the class of mono-pseudocontractive mappings (related to the class of monotone mappings) which is the analogue of class of pseudocontractive mappings in Hilbert spaces. This complements the results of $[24,25,37]$ for pseudocontractive mappings (related to the class of accretive mappings) in Banach spaces. 


\section{Acknowledgment}

This article was funded by the Deanship of Scientific Research (DSR), King Abdulaziz University, Jeddah. N. Shahzad acknowledges with thanks DSR for financial support.

\section{References}

[1] Y. I. Alber, Metric and generalized projection operators in Banach spaces: properties and applications, Lecture Notes in Pure and Appl. Math., Dekker, New York, (1996). 2, 2, 2.1, 2.3, 2, 2.4

[2] M. A. Alghamdi, M. A. Alghamdi, N. Shahzad, H.-K. Xu, The implicit midpoint rule for nonexpansive mappings, Fixed Point Theory Appl., 2014 (2014), 9 pages. 1

[3] E. Blum, W. Oettli, From optimization and variational inequalities to equilibrium problems, Math. Student, 63 (1994), 123-145. 2.5

[4] F. E. Browder, W. V. Petryshyn, Construction of fixed points of nonlinear mappings in Hilbert spaces, J. Math. Anal. Appl., 20 (1967), 197-228. 1

[5] C. E. Chidume, S. A. Mutangadura, An example of the Mann iteration method for Lipschitz pseudocontractions, Proc. Amer. Math. Soc., 129 (2001), 2359-2363. 1

[6] C. E. Chidume, N. Shahzad, Strong convergence of an implicit iteration process for a finite family of nonexpansive mappings, Nonlinear Anal., 62 (2005), 1149-1156. 1

[7] C. E. Chidume, H. Zegeye, N. Shahzad, Convergence theorems for a common fixed point of a finite family of nonself nonexpansive mappings, Fixed Point Theory Appl., 2005 (2005), 233-241. 1

[8] A. Genel, J. Lindenstrauss, An example concerning fixed points, Israel J. Math., 22 (1975), 81-86. 1

[9] K. Goebel, S. Reich, Uniform convexity, hyperbolic geometry, and nonexpansive mappings, Marcel Dekker, New York, (1984). 1

[10] O. Güler, On the convergence of the proximal point algorithm for convex optimization, SIAM J. Control Optim., 29 (1991), 403-419. 1

[11] B. Halpern, Fixed points of nonexpanding maps, Bull. Amer. Math. Soc., 73 (1967), 957-961. 1, 1

[12] H. Iiduka, W. Takahashi, Strong convergence theorems for nonexpansive mappings and inverse-strongly monotone mappings, Nonlinear Anal., 61 (2005), 341-350. 1, 1

[13] S. Ishikawa, Fixed points by a new iteration method, Proc. Amer. Math. Soc., 44 (1974), 147-150. 1

[14] S. Ishikawa, Fixed points and iteration of a nonexpansive mapping in a Banach space, Proc. Amer. Math. Soc., 59 (1976), 65-71. 1

[15] S. Kamimura, W. Takahashi, Strong convergence of proximal-type algorithm in a Banach space, SIAM J. Optim., 13 (2002), 938-945. 2.2

[16] P.-L. Lions, Approximation de points fixes de contractions, C. R. Acad. Sci. Sér. A-B, 284 (1977), 1357-1359. 1, 1

[17] Q.-H. Liu, The convergence theorems of the sequence of Ishikawa iterates for hemicontractive mappings, J. Math. Anal. Appl., 148 (1990), 55-62. 1

[18] P. E. Maingé, Strong convergence of projected subgradient methods for nonsmooth and non-strictly convex minimization, Set-Valued Anal., 16 (2008), 899-912. 2.8

[19] W. R. Mann, Mean value methods in iteration, Proc. Amer. Math. Soc., 4 (1953), 506-510. 1, 1

[20] C. Matinez-Yanes, H.-K. Xu, Strong convergence of the CQ method for fixed point processes, Nonlinear Anal., 64 (2006), 2400-2411. 1

[21] A. Moudafi, Viscosity approximation methods for fixed point problems, J. Math. Anal. Appl., 241 (2000), 46-55. 1

[22] D. Pascali, S. Sburlan, Nonlinear mappings of monotone type, Sijthoff \& Nordhoff International Publishers, Alphen aan den Rijn, (1978). 1, 3

[23] S. Reich, Weak convergence theorems for nonexpansive mappings in Banach spaces, J. Math. Anal. Appl., 67 (1979), 274-276. 1

[24] S. Reich, Strong convergence theorems for resolvents of accretive operators in Banach spaces, J. Math. Anal. Appl., 75 (1980), 287-292. 1, 4.3

[25] N. Shioji, W. Takahashi, Strong convergence of approximated sequences for nonexpansive mappings in Banach spaces, Proc. Amer. Math. Soc., 125 (1997), 3641-3645. 1, 1, 4.3

[26] W. Takahashi, Nonlinear functional analysis. Fixed point theory and its applications, Yokohama Publishers, Yokohama, (2000). 2

[27] B. S. Thakur, R. Dewangan, M. Postolache, New iteration process for pseudocontractive mappings with convergence analysis, Fixed Point Theory Appl., 2015 (2015), 14 pages. 1

[28] R. Wittmann, Approximation of fixed points of nonexpansive mappings, Arch. Math. (Basel), 58 (1992), 486-491. 1

[29] H.-K. Xu, Another control condition in an iterative method for nonexpansive mappings, Bull. Austral. Math. Soc., 65 (2002), 109-113. 2.7

[30] H.-K. Xu, Strong convergence of an iterative method for nonexpansive and accretive operators, J. Math. Anal. Appl., 314 (2006), 631-643. 1 
[31] H.-K. Xu, M. A. Alghamdi, N. Shahzad, The viscosity technique for the implicit midpoint rule of nonexpansive mappings in Hilbert spaces, Fixed Point Theory Appl., 2015 (2015), 12 pages. 1

[32] H.-K. Xu, M. A. Alghamdi, N. Shahzad, The implicit midpoint rule for nonexpansive mappings in Banach spaces, Fixed Point Theory, 17 (2016), 509-517.

[33] Y.-H. Yao, M. Postolache, Y.-C. Liou, Coupling Ishikawa algorithms with hybrid techniques for pseudocontractive mappings, Fixed Point Theory Appl., 2013 (2013), 8 pages.

[34] Y.-H. Yao, N. Shahzad, Strong convergence of a proximal point algorithm with general errors, Optim. Lett., 6 (2012), 621-628.

[35] Y.-H. Yao, N. Shahzad, Y.-C. Liou, Modified semi-implicit midpoint rule for nonexpansive mappings, Fixed Point Theory Appl., 2015 (2015), 15 pages. 1

[36] H. Zegeye, An iterative approximation method for a common fixed point of two pseudocontractive mappings, ISRN Math. Anal., 2011 (2011), 14 pages. 1

[37] H. Zegeye, N. Shahzad, Viscosity Approximation methods for a common fixed point of finite family of nonexpansive mappings, Appl. Math. Comput., 191 (2007), 155-163. 1, 4.3

[38] H. Zegeye, N. Shahzad, A hybrid approximation method for equilibrium, variational inequality and fixed point problems, Nonlinear Anal. Hybrid Syst., 4 (2010), 619-630. 1

[39] H. Zegeye, N. Shahzad, Strong convergence theorems for a finite family of nonexpansive mappings and semigroups via the hybrid method, Nonlinear Anal., 72 (2010), 325-329. 1

[40] H. Zegeye, N. Shahzad, Approximating common solution of variational inequality problems for two monotone mappings in Banach spaces, Optim. Lett., 5 (2011), 691-704. 2.6

[41] H. Zegeye, N. Shahzad, T. Mekonen, Viscosity approximation methods for pseudocontractive mappings in Banach spaces, Appl. Math. Comput., 185 (2007), 538-546. 1

[42] E. Zeidler, Nonlinear functional analysis and its applications, Part II: Monotone Operators, Springer-Verlag, New York, (1990). 1 